\title{
Formal Semantics of Sign Languages
}

\section{Sandro Zucchi*}

Dipartimento di Filosofia, Università degli Studi di Milano via Festa del Perdono

\section{Abstract}

The paper discusses some issues that arise from research on sign languages in the area of formal semantics. Sign languages provide a unique standpoint to investigate semantic phenomena like donkey anaphora, indexical reference shift, and tense. Moreover, they pose a challenge for semantic theories, since movement verbs display gradient properties (semi-continuous variations with semantic import). The paper presents and discusses some accounts that have been proposed.

\section{Introduction}

Research on the grammar of sign languages, whether in phonology, syntax, or semantics, shows, on the one hand, how similar sign languages are to spoken languages, how the structures we find in the grammars of spoken languages are also found in sign language grammars, once we abstract from the different modalities these languages use (phonetic vs. visual); on the other hand, linguistic research on sign languages also reveals how different they are from spoken languages: how features not overtly instantiated or rarely occurring in spoken languages are overtly marked and quite common in sign languages. Through the investigation of these similarities and differences, theoretical issues may be resolved and significant questions may arise concerning the form of natural language grammars. Here, I'll discuss some of these issues and questions coming from research in formal semantics. I'll concentrate on four areas: pronominal anaphora, indexicals, tense, and verbs of motion.

\section{Pronominal Anaphora}

An issue that has engaged formal semanticists for a long time concerns the phenomenon of so-called donkey anaphora, originally pointed out by Geach (1962), in which a pronoun is construed with an indefinite antecedent in a different clause:

(1) a. If a man owns a donkey, he beats it

b. Every man who owns a donkey beats it

c. A man broke the bank at Monte Carlo, and he recently died a pauper.

One question that arises in relation to (1) concerns the nature of the anaphoric relation between the pronoun and its indefinite antecedent. According to some theories, it's a relation of variable binding, namely in the logical forms of (1) the pronouns "he" and "it" are variables bound by quantifiers, where binding involves coindexing with the quantifier, as in $2:^{1}$

(2) $\exists_{i} \operatorname{man}_{i}$ broke the bank at Monte Carlo, and he ${ }_{i}$ recently died a pauper.

According to other theories, the pronouns in (1) are disguised definite descriptions: for example, (1c) is interpreted on a par with (3) below, where the description "the man 
who broke the bank at Monte Carlo" is not itself bound by a quantifier. These theories of donkey anaphora are called e-type theories. ${ }^{2}$

(3) A man broke the bank at Monte Carlo, and the man who broke the bank at Monte Carlo recently died a pauper.

How should one choose between these different approaches to donkey anaphora? Schlenker $(2009,2010 \mathrm{a}, \mathrm{b})$ claims that sign languages provide a way to put them to test. In these languages, the relation between pronominals and their antecedents is marked overtly: anaphoric pronouns are usually expressed by pointing to the spatial locations where the antecedents have been signed. For example, while in English sentence (4) below (from Lillo-Martin and Klima 1991) the relation the pronouns "he" and "him" bear to their antecedents is not overtly marked and needs to be inferred from extra-linguistic clues, in American Sign Language (ASL) the corresponding sentence is disambiguated by the loci of the pronouns (the locations in space to which the index finger points): if the index points to the location where the sign JOHN was signed, then JOHN is the antecedent of the pronoun, while if the index points to the location where the sign BILL was signed, BILL is the antecedent of the pronoun. ${ }^{3}$

(4) John called Bill a Republican and then he insulted him

Lillo-Martin and Klima suggest that the loci of sign language pronouns are realizations of the indices carried by the NPs: sign languages differ from spoken languages since indices are overtly realized in sign languages, but not in spoken languages. Signs carrying the same index must point to the same loci, while signs pointing to distinct loci carry distinct referential indices. ${ }^{4}$

As Schlenker points out, if loci overtly realize indices and binding involves coindexing, the following sentences from French Sign Language (LSF) seem to favor the variable binding account, since the pronouns are coindexed with their indefinite antecedents $(a, b$ are distinct loci to which the pronoun sign IX points, 1 is the speaker locus):

(5) (LSF)

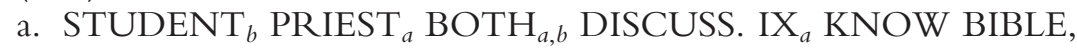
$\mathrm{IX}_{b}$ NOT-KNOW.

"I talked to a student and a priest. He [= the priest] knew the Bible, but he [= the student] didn't know it."

b. EACH-TIME LINGUIST ${ }_{a}$ PSYCHOLOGIST $_{b}$ ALL-THREE $_{b, a, 1}$ TOGETHER WORK, IX ${ }_{a}$ HAPPY BUT IX ${ }_{b}$ HAPPY NOT.

"Whenever I work with a linguist and a psychologist, the linguist is happy, but the psychologist is not happy."

A possible objection to this conclusion is that identity of locus in (5) might express a syntactic relation other than binding between the pronoun and its antecedent. As Heim (1990) points out, although in the e-type analysis the pronoun is not bound by a quantifier, an adequate formulation of the analysis requires that the pronoun be somehow syntactically linked to an antecedent: the description which corresponds to the pronoun must be reconstructed, at least in part, from linguistic material provided by an NP occurring in the discourse. This accounts for the fact that (6a), unlike (6b), cannot be interpreted as saying that every married man is sitting next to his wife, since in (6a) there is no antecedent NP to provide the linguistic material to reconstruct the descriptive content of the pronoun "her": 
(6) a. Every married man is sitting next to her

b. Every man who has a wife is sitting next to her

If this is correct, the e-type theorist might claim that identity of loci between pronouns and indefinite NPs in (5) simply reflects the syntactic link between the pronouns and the NPs providing linguistic material for reconstruction, with no binding involved. As Schlenker points out, however, (7) shows that this is not the case:

(7) (ASL)

$\mathrm{WHEN} \mathrm{ONE}_{a} \mathrm{MEET}_{a, b} \mathrm{ONE}_{b}$

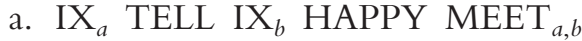

b. IX IXLL IX $_{a}$ HAPPY MEET $_{a, b}$

"When someone meets someone, he tells him that he is happy to meet him"

If identity of locus indicates which NP provides the linguistic material to reconstruct the descriptive content of the pronoun, in principle it should be possible for distinct pronouns to point at the locus of the same NP and still yield an interpretation in which they have disjoint reference. ${ }^{5}$ In fact, only the pointing indicated in (a)-(b), in which the pronouns point at different loci, is possible. Notice, on the other hand, that under the variable binding analysis this is expected: if both pronouns point at the same locus, they instantiate the same logical variable and this requires them to have the same reference, thus yielding a pragmatically anomalous reading in which the same individual is happy to meet herself. Thus, if Schlenker is right, data from sign languages provide crucial evidence favoring a variable binding approach over an e-type approach to donkey anaphora.

\section{Indexicals}

The philosopher David Lewis once remarked that we could speak a language in which "As for him, I'm hungry" means the same as "He's hungry", but we don't: in English, we cannot use a first person pronoun to refer to someone other than the speaker of the context of utterance. ${ }^{6}$ An operator like "as for him" in Lewis's imaginary language requires that we evaluate the sentence it modifies, "I'm hungry", not relative to the context in which it is uttered, but relative to another context in which the speaker is the referent of the pronoun "him". Operators of this sort are called "monsters" by David Kaplan. ${ }^{7}$ Kaplan, like Lewis, thinks that there are no monsters in English. But what about other natural languages? Are there some natural languages with operators that can shift the reference of indexicals like "I"?

Empirical evidence suggesting that monsters do occur in some spoken languages is brought up by Schlenker (1999). Schlenker observes that in Amharic, a Semitic language of Ethiopia, the word for "I", when it is embedded in the complement clause of an attitude verb as in (8), does not refer to the speaker of the context of utterance, but to the subject of the matrix clause: ${ }^{8}$

(8) john Jägna näNN yt-lall

John hero am-I says-3sg.m

"John says that he is a hero"

Notice that the reference shift of Amharic "I" cannot be analyzed as an instance of quotation, since the indexical pronoun corresponding to "me" in (9) is interpreted with 
respect to the actual context of utterance, contrary to what we would expect if the complement clause were quoted:

(9) alðtazzäzäNN alä

I-will-not-obey-me he-said

"He refused to obey me"

More recently, Ananad and Nevins (2004) claimed that in Zazaki (an Indo-Iranian language) and Slave (an Athabaskan language) indexicals may shift their reference in the complements of verbs like "say", "tell", and "want".

Indexical reference shift in spoken languages has been analyzed by Schlenker (1999, 2003) by supposing that attitude verbs are monsters in Kaplan's sense. More precisely, Schlenker (in one version of his proposal) supposes that, at LF, attitude verbs like "say" are universal quantifiers over contexts that can bind context variables in their scope, and that shiftable indexicals like Amharic "I" contain a context variable that can be bound by the attitude verb. To get an intuitive grasp of his proposal, let's see how it works applied to Amharic. Sentence (8) is represented thus at LF:

$$
S A Y_{(J o h n, t, w)} \text { c hero }(I(c), \text { time }(c), \text { world }(c))
$$

In this formula, $c$ is a variable ranging over contexts, $t$ and $w$ are terms denoting a time and a world, $I(c)$ is the representation of Amharic "I" denoting the agent of the context denoted by $c$, and time $(c)$ and world $(c)$ denote the time and the world of this context, respectively. According to the interpretation Schlenker proposes for SAY, the formula is true in a context iff, for every context c' compatible with what John says at the time and world denoted by $t$ and $w$, the formula hero $(I(c), \operatorname{time}(c)$, world $(c))$ is true when $c$ denotes c'. The key idea here is that a context c' compatible with what an individual $x$ says in a world $\mathrm{w}$ at a time $\mathrm{t}$ is one in which $\mathrm{x}$ is the speaker of c'. As a consequence, (8) is correctly predicted to be true true if John says "I'm a hero" at the time and world denoted by $t$ and $w$. On the other hand, the representation of English "I" does not contain a context variable bindable by SAY, but is represented as a constant term referring to the speaker of the context of utterance of the report. Thus, (11) means that John says of the speaker that he is a hero.

(11) John says that I am a hero

Let's now turn to sign languages. Indexical reference shift is also quite common in sign languages and has been extensively described in the literature, although until recently it was not discussed in connection with the existence of monsters. ${ }^{10}$ Here's an example from Catalan Sign Language (LSC) reported by Quer (2005):

$$
\begin{aligned}
& \frac{t}{\text { IXa MADRID }_{m}} \text { MOMENT JOAN }_{i} \frac{\text { RS }-i}{\text { THINK IX-1 STUDY FINISH HERE }_{b}} \text { (LSC) } \\
& \text { "When he was in Madrid, Joan thought he would finish his study here } \\
& \text { (in Barcelona)" }
\end{aligned}
$$

In (12), the first person pronoun IX-1 is interpreted as referring to Joan and not to the signer. This shift in reference of the pronoun is indicated by non-manual signs co-articulated with the manual signs. For example, while uttering the sentence that contains the pronoun, the signer may shift the body slightly toward the locus where the name coreferential with the pronoun was previously signed (this is indicated in (12) by the line RS- $i$ on the part of the sentence over which the non-manual sign extends). Notice that the complement sentence of THINK in (12) cannot be understood as a quotation (direct 
discourse), since the indexical HERE refers to the location of the signer and not to the location of the subject of report. ${ }^{11}$

Although (12) is not a case of direct discourse, the kind of non-manual features observed in (12) are also used to express direct discourse. For example, in the following Italian Sign Language (LIS) narration of Aesop's Fable "The Tortoise and the Hare" reported in Zucchi (2004), the signer appears to be quoting what the different characters say by shifting the body toward the point in space identified with the hare and the point in space identified with the tortoise. ${ }^{12}$ Notice that the first utterance contains a first person pronoun that does not include the narrator: $\rightarrow$ body shifts right
a. HARE JUMP GET-CLOSE INDEX START ASK WE-TWO CONTEST CAN
The hare, jumping, gets close to her (the tortoise) and starts asking: "can we have a contest?"
b. TORTOISE CONTEST HOW
The tortoise: "which kind of contest?"
c. CONTEST RUN ARRIVE FIRST WHO
"A running contest to see who arrives first"

How should one analyze indexical shift in sign languages and how is it related to indexical shift in spoken languages? Given that in sign languages non-quotational occurrences of indexical shift (like the pronoun IX-1 in (12)) and (apparently) quotational occurrences (like the pronoun WE in (13)) are realized by the same set of non-manual features, it may be desirable to analyze them as instances of a single underlying grammatical device. Unified analyses of this sort have been proposed by Lillo-Martin (1995) and Quer (2005).

Lillo-Martin assumes that ASL has a point of view verb (POV), whose presence is signaled by the non-manual features characterizing reference shift. This verb takes sentential complements and can indirectly bind occurrences of first person indexicals in its scope. Here's an example:

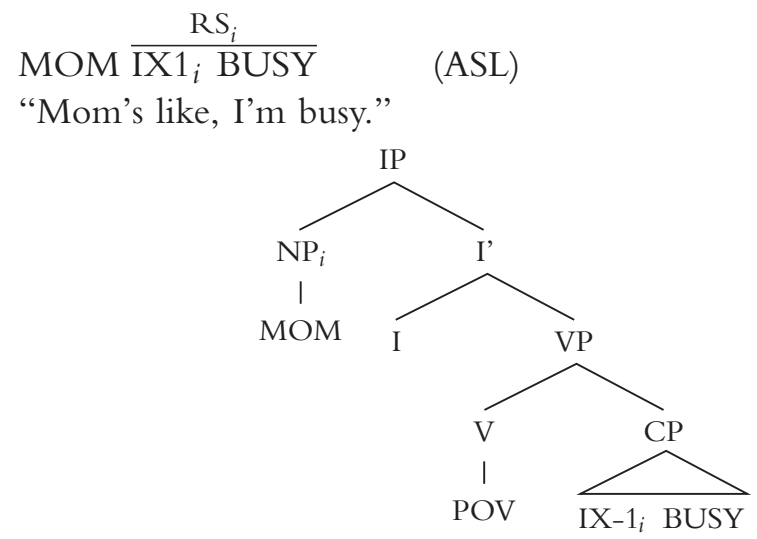


Lillo-Martin's proposal was made at a time when formal semantic work on monsters in spoken languages was yet to come. A natural move, suggested by Quer, is to analyze indexical reference shift in sign languages along the lines proposed by Schlenker for indexical shift in Amharic. Applied to Lillo-Martin's analysis, this means that (14) is represented in this way at LF: ${ }^{13}$

(15) $\operatorname{POV}_{(M O M, t, w)}$ c busy $(I(c)$, time $(c)$,world $(c))$

The formula is true in a context iff, for every context c' compatible with mom's point of view at the time and world denoted by $t$ and $w$, the formula bus $y(I(c)$, time $(c)$, world $(c))$ is true when $c$ denotes c'. Again, the idea here is that a context c' compatible with an individual $x$ 's point of view in a world $\mathrm{w}$ at a time $\mathrm{t}$ is one in which $\mathrm{x}$ is the speaker/signer of c'. As a consequence, (15) is correctly predicted to be true if MOM says "I'm busy" (or signs the corresponding sign language sentence) at the time and world denoted by $t, w$.

Quer's (2005) proposal tries to overcome a technical problem with Lillo-Martin's analysis pointed out by Lee et al. (1997). According to Lillo-Martin, the POV takes a CP-complement. Thus, when an explicit verb of saying is present, as in (16) below, Lillo-Martin assumes that the subject of the POV verb is a null pronominal of the kind occurring in pro-drop languages:

$$
\begin{aligned}
& \mathrm{JOHN}_{i} \mathrm{TELL}_{j} \text { MARY }_{j} \frac{\mathrm{RS}_{i}}{\mathrm{I} \text { WANT GO }} \\
& \text { "John told Mary: 'I want to go.'” }
\end{aligned}
$$

\section{$\left[{ }_{I P} \mathrm{JOHN}_{i}\left[I_{I^{\prime}}\left[V P\right.\right.\right.$ TELL MARY $\left[{ }_{C P}\left[{ }_{I P} \operatorname{pro}_{i}\left[I_{I^{\prime}}\left[V P\right.\right.\right.\right.$ POV $\left[{ }_{C P} \mathrm{I}_{i}\right.$ WANT GO $\left.\left.\left.\left.\left.\left.]\right]\right]\right]\right]\right]\right]$}

As Lee and his co-authors point out, however, this analysis predicts that the subject of the POV predicate occurring with a verb of saying could be an overt NP, contrary to what (18) shows:

$$
\text { *JOHN TELL } \text { MARY }_{j} \text { BILL }_{i} \frac{\mathrm{RS}_{i}}{\mathrm{I}_{\mathrm{WANT}} \mathrm{GO}}
$$

Notice that we cannot avoid the problem by assuming that the covert POV predicate fails to license overt subjects, since according to Lillo-Martin the subject MOM in (14) is an overt subject of the POV predicate. ${ }^{14}$

In Quer's proposal, the point of view operator (PVOp) is not an attitude verb, but an operator sitting in a very high projection of the functional structure of the clause (Speech Act Phrase). Since the PVOp is not a predicate, it does not require one to posit a subject position for it. Moreover, a claimed advantage of this proposal is that it can naturally account for the fact that in sign languages indexical shift does not seem to be restricted to complement clauses. For example, in Italian Sign Language sentence (19) reported in Zucchi (2004), the verb DONATE in the main clause carries first person subject agreement, but the clause means that Gianni is the one who will give you a book as a present: ${ }^{15}$

$$
\begin{aligned}
& \frac{\text { when }}{\text { GIANNI }_{i} \text { ARRIVE, BO OK } 1-\text { DONATE }_{i}} \text { (LIS) } \\
& \text { "When Gianni will come, he'll give you a book as a present." }
\end{aligned}
$$

Quer reports a similar example of indexical shift in a main clause from LSC with an overt occurrence of "I". Occurrences of this sort are expected if, as Quer claims, indexical shift is due to the presence of a sentential operator sitting in a high functional projection of 
the clause, while it is not obvious how to account for them if it is due to the presence of a complement taking verb, as Lillo-Martin claims.

While Quer's suggestion avoids some of the problems that arise for Lillo-Martin's proposal, it also leaves some important issues open. Quer claims that his PVOp is an operator on contexts a la Schlenker. Notice, however, that, while in Lillo-Martin's proposal it is relatively straightforward how to extend Schlenker analysis of "say" to the POV, that is not the case in Quer's proposal. One problem, noted by Quer himself, is raised by structures like (12), where an attitude verb co-occurs with the non-manual features realizing the PVOp. In this case, Quer suggests that the PVOp moves up in the structure to incorporate into the main verb. If so, how is the result of incorporation to be interpreted? Here are some further questions. If the PVOp is a sentential operator, presumably it only takes a sentential argument, but Schlenker's attitude operators also take an argument corresponding to the bearer of the attitude. So, how can one extend Schlenker's semantics to the PVOp? Aside from these technical issues, notice that, if Quer's analysis is to be extended to (19), it is not clear how the shift here can be due to an attitude operator a la Schlenker, since (19) doesn't seem to involve a propositional attitude at all (if it does, it involves a notion of point of view rather different from that of examples like (12)-(13) and (14)). ${ }^{16}$ Finally, if indeed in sign languages indexical reference shift is not restricted to complement clauses, why is there this typological difference between sign languages and spoken languages?

\section{Tense}

Now, consider the following sentences of Italian Sign Language:

(20) GIANNI HOUSE BUY "Gianni is buying a house."

(21) TIME-AGO GIANNI HOUSE BUY

"Some time ago Gianni bought a house."

\section{(22) TOMORROW GIANNI HOUSE BUY}

"Tomorrow Gianni will buy a house."

One difference between these LIS sentences and their English translations is that, while the English verbs are inflected for tense, in LIS the sign for the verb appears in its citational form. Similar facts have also been observed for American Sign Language (ASL) and have led some authors to conclude that these sign languages, on a par with spoken languages like Chinese, lack tense inflection. ${ }^{17}$

A systematic investigation of how temporal interpretation is determined in ASL, under the assumption that ASL is tenseless, is provided in Rathmann (2005). One way temporal reference is introduced in ASL is by means of time adverbs, as in LIS (21)-(22). When a time adverb is not overtly present, how is the event described by the sentence located in time? According to Rathmann, temporal interpretation is determined through what Smith (2003) calls the deictic, anaphoric and narrative patterns. All three patterns are governed by principles that are operative in spoken languages as well.

In the deictic pattern, temporal interpretation is achieved by means of a pragmatic default principle, the deictic principle, by which, in absence of explicit or contextual overriding factors, unbounded situations are located at the utterance time and bounded situations are located before the utterance time. Examples of the application of this principle are the ASL 
sentences in (23)-(24) below (when they are not understood as referring back to a previously established reference time): the sentences in (23) describe unbounded situations (states) and thus John is understood to know history and be angry at the time of utterance, whereas the sentences in (24) describe bounded situations (accomplishments and achievements) and thus John's arrival and his salmon cooking are understood as occurring in the past. Similar facts are also reported for tenseless languages like Mandarin Chinese.

(23) a. JOHN KNOW HISTORY (ASL)

"John knows history"

b. JOHN BE-ANGRY

"John is angry"

(24) a. JOHN ARRIVE ONE-HOUR-twist (ASL)

"John arrived in an hour"

b. JOHN COOK S-A-L-M-O-N

"John cooked salmon"

The anaphoric pattern is governed by the static principle of interpretation, according to which the reference time of a sentence describing an unbounded situation is equal to the reference time of the immediately preceding sentence. The narrative dynamism principle, characteristic of the narrative pattern, requires, on the other hand, that the reference time of a sentence describing a bounded situation be after the reference time of the immediately preceding sentence. ${ }^{18}$ Both principles may be seen at work in ASL sentences (25) below: the predicates RUN FINISH, WALK FINISH and REST FINISH are predicates of bounded situations, so the walking is understood as coming after the running and the resting after the walking; on the other hand, the situation described by "NICE DAY" is understood as holding during the resting. ${ }^{19}$

$$
\begin{aligned}
& \frac{\mathrm{t}}{\mathrm{JOHN}_{i}} \frac{\mathrm{rhq}}{\text { YESTERDAY DO++ }} \text { pro }_{i} \text { RUN FINISH. pro } i \text { WALK FINISH. } \\
& \text { pro }_{i} \text { REST FINISH. NICE DAY (ASL) } \\
& \text { "Yesterday, John ran, and then walked, and then rested. It was a nice day." }
\end{aligned}
$$

As far as I know, all reported sign languages share this property of ASL and LIS of having unmarked forms of verbs that, under appropriate circumstances, can be used to report present, past or future events. If this is correct, some principles of a pragmatic nature are indeed required in order to account for how temporal interpretation is obtained in these cases. The issue of what pragmatic principles determine the interpretation of the unmarked form, however, is distinct from the issue whether sign languages lack tense inflection or not. Let's consider ASL again. Neidle et al. (2000) have claimed that ASL has a set of lexical tense markers located in the head position of TP. One example of these markers is the sign FUTURE tns $_{\text {in }}$ ASL sentence (26):

(26) JOHN FUTURE tns BUY A HOUSE (ASL)

"John will buy a house."

As Neidle and her coauthors point out, the claim that these lexical items are indeed grammatical tense markers and not time adverbs is supported by the fact that they can be distinguished from time adverbs both from a distributional point of view and from an articulatory point of view. For example, the position in which FUTURE occurs in (26) is also the 
position in which modals occur in ASL, while standard time adverbs like TOMORROW cannot occur in the same position. Moreover, the sign FUTURE in (26) cannot be modified to express the degree of distance from the present, while the same sign in other positions can be articulated with the hand staying closer or further away from the body depending on the nearness of the future time. In English, time adverbs like 'in the future' may be specified for the degree of distance from the present ('in the near future', 'in the distant future'), while tense inflection cannot be specified in the same way. Assuming that ASL is like English in this respect, the lack of modification for the sign FUTURE in (26) may thus be taken as evidence that this sign is a grammatical tense and not an adverb.

If it is correct to claim that ASL has lexical tense markers, one possibility, suggested by Neidle and her coauthors, is that the unmarked verb form occurring in ASL sentences without a lexical tense marker is syntactically in the present tense (which, like present tense in spoken languages, may sometime refer to times other than the time of utterance). ${ }^{20}$ If we follow this suggestion, then ASL is a tense-inflected language, which simply happens not to mark present tense overtly.

According to Zucchi (2009), this is exactly the way things are in a variety of Italian Sign Language attested in the Napoli-Salerno area of Southern Italy. One way of conveying temporal information in this variety of LIS is by means of non-manual features co-occurring with the verb. Sentences (27)-(29) below are an instance of this:

GIANNI HOUSE $\overline{\text { shoulder straight }}$
"Gianni is buying a house."

$$
\begin{aligned}
& \text { GIANNI HOUSE } \overline{\text { shoulder backward }} \\
& \text { "Gianni bought a house." } \\
& \text { shoulder forward } \\
& \text { GIANNI HOUSE } \overline{\text { BUY }} \\
& \text { "Gianni will buy a house." }
\end{aligned}
$$

In these sentences, the position of shoulder while the verb is being signed indicates that the action is present, past, or future: if the shoulder is aligned with the rest of the body, the action is claimed to be taking place at the time of utterance; if the shoulder is tilted backward, the action is claimed to take place before the time of utterance; if the shoulder is tilted forward, the action is claimed to take place after the time of utterance. ${ }^{21}$ These data suggests that the view that LIS lacks grammatical tense should be reconsidered. The position of the shoulder co-occurring with the sign of the verb seems to play the same role as tense inflection on the verb in spoken languages like Italian and English. What changes is simply how grammatical tense is marked: by means of suffixes or stem modification in Italian and English and by means of a suprasegmental (non-manual) element, the position of the shoulder, in LIS. If this is correct, then, given that (20)-(22) above are signed with the shoulder aligned with the body, they are present tense sentences.

Zucchi's account is couched in terms of the formal analysis of tense proposed in Heim (1997). In this analysis, the head of TP at LF contains a free time variable denoting the time of utterance, which, depending on the type of tense, is required to precede, follow, or be identical to, the value of the time variable introduced by the verb (corresponding to the event time). The data in (21)-(22) are then accounted for by supposing that LIS time adverbs like 
TIME-AGO and TOMORROW are able to bind the variable in T. Thus, for instance, LIS present tense sentence (21) is represented as (30) at LF, yielding the desired interpretation:

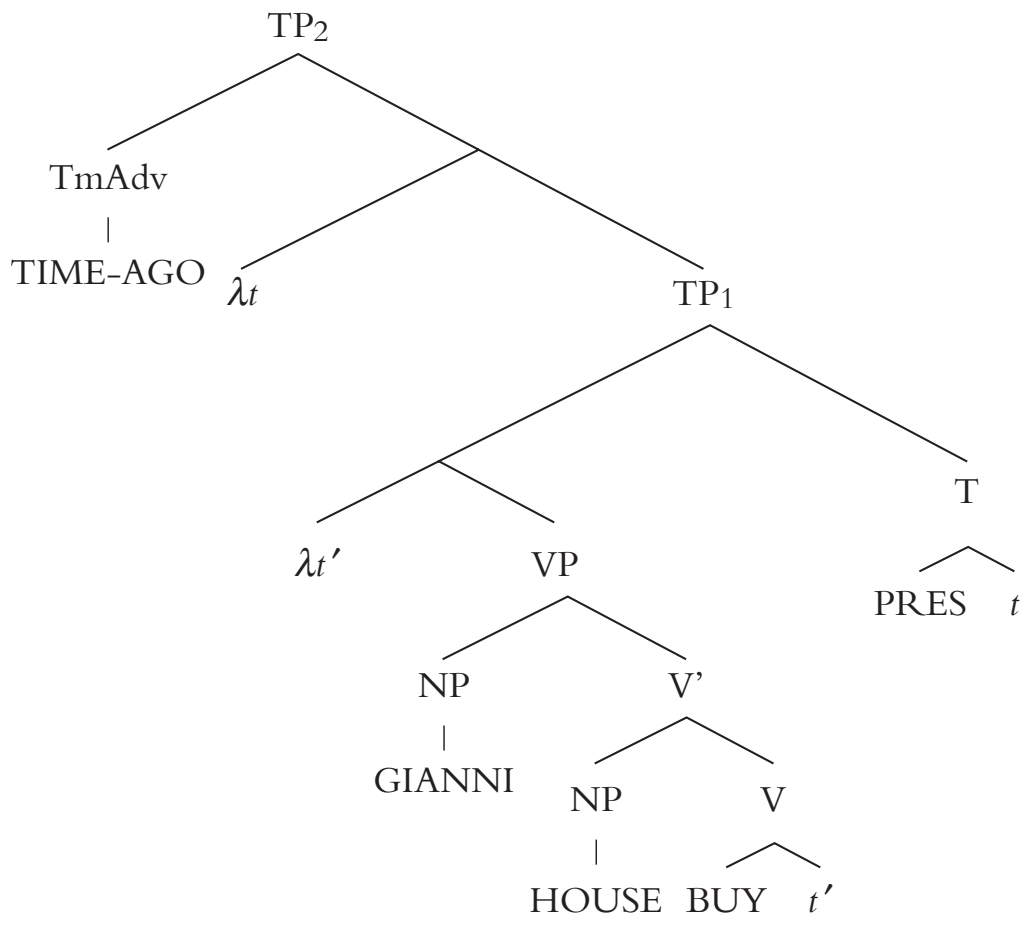

Notice that, in LIS, past and future inflections signaled by the shoulder position cannot co-occur with time adverbs like TIME-AGO and YESTERDAY. Thus, for instance, if we add past and future inflections to the verb in (21)-(22), the resulting sentences are anomalous:
a. *TIME-AGO GIANNI HOUSE $\frac{\text { past }}{\mathrm{BUY}}$
b. *TOMORROW GIANNI HOUSE $\frac{\text { fut }}{\mathrm{BUY}}$

This is accounted for in Zucchi's analysis by suggesting that the variable introduced by past and future tense inflection is rigidly anchored to the utterance time, and thus binding by a time adverb cannot yield a coherent interpretation. ${ }^{22}$

If this proposal is correct for LIS, and some version of it can be extended to ASL tenses, then, contrary to what Rathmann supposes, these sign languages are somewhat more similar to tense inflected languages like English or Italian than to tenseless languages like Chinese. These alternative analyses of tense in sign languages raise different typological questions. If Rathmann is right, the question is why sign languages systematically lack tense inflection. If, on the other hand, the picture proposed by Neidle and her coauthors for ASL and by Zucchi for LIS is representative of the way tense works in sign languages, the question is why the use of the present to talk about past or future events is so widespread in sign languages, while it is restricted to particular stylistic registers (like historical present and futurate uses of the present) in spoken languages. 


\section{Verbs of Motion and Location}

I conclude this report by describing some issues that concern the meanings of verbs of motion and location in sign languages, focusing on so-called classifier predicates in particular. While these predicates are well known and extensively discussed in the sign language literature $^{23}$ there is no published work about them in formal semantics, although they pose what is perhaps the most formidable challenge for formal semanticists working on sign languages.

Informally, classifier predicates may be seen as made up by two components that are simultaneously articulated:

- a handshape specific for a class of objects (the classifier),

- a movement in the signing space (the root).

The movement may depict the movement in real space performed by an object in the class referred to by the handshape (yielding a classifier predicate of motion) or it may indicate the location of the object in real space (yielding a locative classifier predicate).

An example of an ASL sentence containing a classifier predicate of motion is given in Figure 1 below, from Valli and Lucas (2000), in which a sign with a 3-handshape moves from right to left in front of the signer, with the palm facing in. The 3-handshape is an ASL classifier for vehicles and the movement from right to left indicates that the vehicle, a car in this case, drove past. The mimetic character of classifier predicates, the fact that they are used to reproduce the movements or the locations of objects in space, has led some authors, like Macken et al. (1993) and Cogill-Koez (2000), to suggest that sign languages are dual-representation languages, employing both a linguistic mode of communication, when frozen signs are used, and a schematic visual representation mode, exemplified by constructions with classifier predicates. At the opposite end is the analysis proposed in Supalla (1982), where both classifier handshape and movement are analyzed as linguistic morphemes (or as combinations of morphemes) which are articulated simultaneously.

The linguistic character of classifier handshapes is supported by a robust body of evidence showing that they are conventional (they differ in different sign languages), combine with each other to form complex expressions via rule-governed processes (Liddell and Johnson

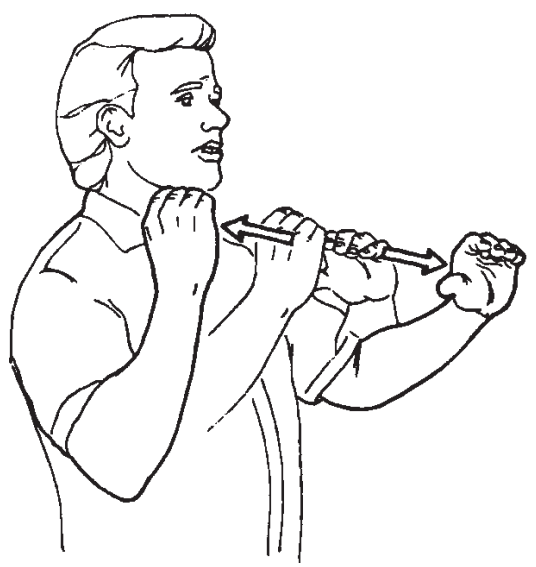

CAR

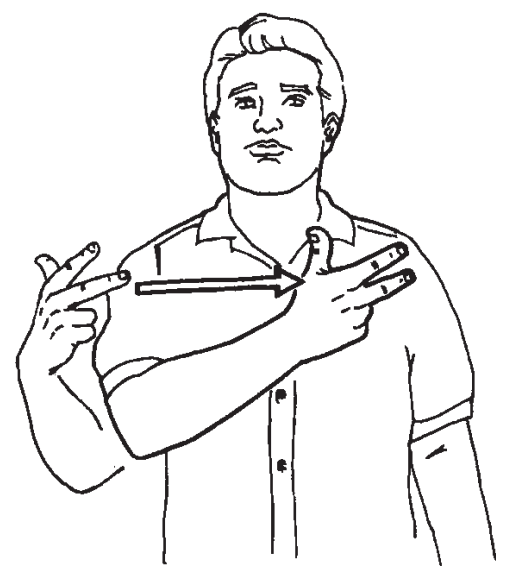

CLvehicle-DRIVE-PAST

Fig 1. A car drove past. The image is taken from Valli and Lucas (2000). Reproduced by permission of Gallaudet University Press. 
1987), and interact with other grammatical rules (Benedicto and Brentari 2004). However, Emmorey and Herzig (2003) provide experimental evidence that, while classifier handshapes are categorical, namely variations in handshape do not correspond in a continuous way to variations in real world objects, the placement of these handshapes in space is not: variations in the positions occupied by a classifier are taken to correspond in a quasi-continuous way to variations in the position of real world objects. Moreover, further experimental data in Giacomello (2007) indicate that handshape movement variations in classifier predicates of motion are also taken to correspond in a quasi-continuous way to variations in the movement of real world objects. This suggest that, unlike classifier handshapes, handshape position in locative classifier predicates and handshape movement in classifier predicates of motion are non-linguistic. This conclusion is puzzling, since it means that in ASL sentence (32) the same sign displays both linguistic and non-linguistic features. How can this be?

(32) CAR $\mathrm{CL}_{\text {vehicle }}$-DRIVE-PAST (ASL)

"a car drove past"

Cecchetto and Zucchi (2006) propose an analysis of classifier predicates of motion that tries to account for their double nature. According to this analysis, classifier predicates of motion are indexical predicates, similar to English (33):

(33) moves in a way similar to this.

The movement in classifier predicates of motion is no linguistic morpheme, but plays the role of a demonstration which provides the reference for an indexical term in the logical representation of the predicate. For example, the movement of the classifier in (32) is a demonstration that illustrates the kind of movement the vehicle underwent. Notice that, in this analysis, classifier predicates of motion, like the predicate in (33), are linguistic items. An indexical account may also be extended to locative classifier predicates: in this case what is demonstrated is the location in the signing space that corresponds to the position of the real world object. This means that, in principle, sign languages are not dual representation languages any more than spoken languages are (although sign languages may make a more extensive use of demonstrative predicates like (33)).

The logical form assigned to (32) in this analysis is given in (34) and the interpretation of the classifier predicate is given in (35) (where $c l_{i, k}^{c_{A}}$ stands for the classifier token $c l_{i, k}$ signed by the agent of c):

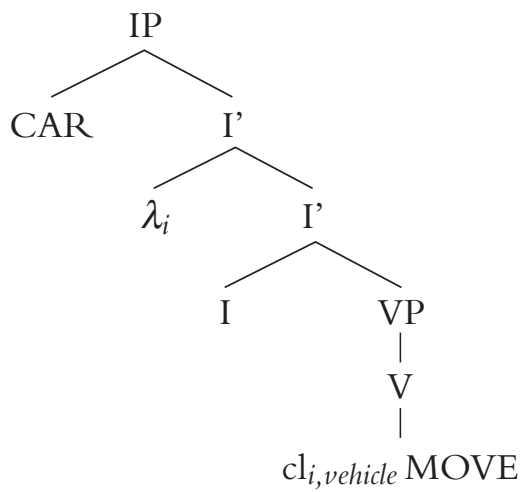

(35)

$\lambda e\left[\operatorname{move}\left(x_{i, v e h i c l e}, e\right) \wedge \operatorname{similar}_{S \rightarrow L}\left(\right.\right.$ dthat $\left[\right.$ the movement of $\left.\left.\left.c_{i, v e h i c l e}^{c_{A}}\right], e\right)\right]$ 
According to this interpretation, the classifier verb in 5 is a predicate of events of a vehicle's moving, where the movement is similar, in relevant respects, to that which is demonstrated while moving the classifier. ${ }^{24}$

Even if (35) is on the right track, however, the analysis clearly needs to be refined. For one thing, Supalla (1990) has shown that, in some cases, the movement associated with the classifier is constrained in such a way that it can represent the manner of locomotion, while it cannot simultaneously represent the path and direction of locomotion (although it would be physically possible for the signer to do so). This means that an adequate interpretation for classifier predicates cannot simply refer to the movement performed while signing the predicate as in (35), but has to distinguish between the manner, path and direction of the movement. Not surprisingly, in the area of sign language verb semantics, as in all other areas briefly touched upon here, much remains to be done for the semanticist.

\section{Wrapping Up}

In this report, I described current work on the formal semantics of sign languages by concentrating on pronominal anaphora, indexicals, tense, and verbs of motion. Despite the focus on an area of research that has developed recently, some topics were left out for which formal semantics analyses have been proposed (one example is the work on relative clauses by Cecchetto et al. 2006). Other topics, like quantification and aspect have been investigated from a semantic standpoint though no formal semantic analysis has yet been given (see, for example, Petronio 1995 for quantification and Meir 1999, Wilbur 2003, Schalber 2006, and references therein for aspect). Other phenomena, like definiteness, specificity, genericity, focus, conditionals and modals, which in sign languages display distinctive features, are waiting for full semantic investigation.

\section{Short Biography}

Alessandro Zucchi teaches at the University of Milan. His research area is formal semantics. He holds a $\mathrm{PhD}$ in linguistics from the University of Massachusetts at Amherst.

\footnotetext{
Notes

* Correspondence address: Sandro Zucchi, Dipartimento di Filosofia, Università degli Studi di Milano via Festa del Perdono 7, 20122, Milano, Italy. E-mail: alessandro.zucchi@unimi.it

1 Depending on the theory, the quantifier binding the pronoun is either introduced by the indefinite itself (Groenendijk and Stokhof 1990, 1991, Chierchia 1995), or by the way the LF-structures in which the indefinite occurs are construed (Heim 1982), or by the truth-conditions of the Discourse Representations into which the sentences containing the indefinite are mapped (Kamp 1981; Heim 1982).

2 See, among others, Evans (1977, 1980), Parsons (1978), Cooper (1979), Heim (1990).

3 Here, I follow the convention of using capitalized words to gloss signs.

4 See Lillo-Martin and Klima (1991) and Lillo-Martin (2002).

5 Notice that, by itself, the linguistic material provided by the antecedent may not be sufficient to distinguish the referents of pronouns, as (7) and (i) show:

(i) when a bishop meets a bishop, he blesses him.

Thus, under the e-type analysis, some independent device is needed to account for why the pronouns in (i) and (7) have disjoint reference.

6 Actually, Lewis (1980) imagines a language in which "As for you, I'm hungry" means the same as "you are hungry", but the example in the text makes the same point.

7 Kaplan (1977).
} 
8 Schlenker also argues that English indexicals like "in two days" can shift their reference, but this claim is disputed by Anand and Nevins (2004).

9 Indexical shift is also reported to occur in complement clauses of Aghem (Hyman 1979) and Navajo (Speas 2000).

10 Indexical shift is discussed in the sign language literature as part of a more general phenomenon called "role shift". In addition to the references cited here, see Emmorey and Reilly (1995) and references therein.

11 This does not mean that only first person indexicals shift in sign languages. Indeed, Quer reports examples from LSC showing that second person pronouns, locative indexicals and temporal indexicals can also shift.

12 Notice that in (13) the body shift also occurs on the non-quotational part describing the jumping of the hare. Presumably, this is because the signer, when describing the actions of the tortoise and the hare, is actually playing the role of these characters.

${ }^{13}$ Here, I'm abstracting from the details of Lillo-Martin's proposal, in which the indirect binding is obtained through an operator in the specifier of the complement CP.

14 An anonymous referee suggests that one way of avoiding the problem raised by (16) for Lillo-Martin's proposal is to assume that non-manual markings indicating the shift signal either the presence of an implicit attitude predicate quantifying over contexts a la Schlenker or the presence of an explicit attitude predicate that also quantifies over contexts. According to this proposal, the function of the non-manual markings in (16) is not that of indicating the presence of a covert attitude predicate (as in (14)), but that of indicating that the overt attitude predicate TELL is a quantifier over contexts (thus capable of inducing indexical shift). Since in absence of the non-manual markings indicating the indexical shift, the first person pronoun in (16) refers to the signer, one consequence of this analysis is that attitude verbs in sign languages have a double life: they can either be universal quantifiers over contexts (thus capable of inducing the shift) or universal quantifiers over worlds as in the standard analysis (in which case they do not induce the shift). One question that arises in this case is why, in spoken languages where indexical shift occurs, one never finds overt morphology marking the distinction between attitude verbs that quantify over contexts and attitude verbs that quantify over worlds.

15 LIS verb DONATE displays first person agreement when the movement of the verb originates from the signer's body, while, if the movement originates from a point in the signing space where a proper name was previously signed, the verb displays third person agreement. In taking the spatial orientation of verbs to be the overt expression of person agreement, I follow Padden (1988), Bahan (1996) Neidle et al. (2000), and others. According to some authors, sign languages mark the distinction between first and non-first person, but make no distinction between second and third person (see, for example, Meier 1990 on ASL).

16 This question also arises for the version of Lillo-Martin's proposal sketched here.

17 See Friedman (1975) and Rathmann (2005) for ASL, and Pizzuto et al. (1995) for LIS.

18 The particular formulations Rathmann assumes for these principles are taken from Smith (2004). However, the principles are clearly reminiscent of the way reference time is updated in DRT (see Kamp and Reyle 1993).

19 The non-manual feature "rhq" indicates the grammatical facial expression for rhetorical questions, "++" indicates that the sign is articulated twice, and $\operatorname{pro}_{i}$ is an invisible pronoun.

20 This is the case for the historical present and for futurate uses of the present.

21 Similar facts are reported by Cruz Aldrete (2008) for Mexican Sign language: past and future tenses on the verb may be marked non-manually by a slight backward/ forward movement of the body while signing the verb. Unlike for LIS, however, this type of tense marking optionally co-occurs with time adverbs like YESTERDAY, TOMORROW, etc. I'll come back to this feature of LIS in a moment.

${ }^{22}$ Zucchi argues that some tenses in spoken languages are also deictic in the same way, for example the passato remoto in Italian.

23 Seminal work on this topic is Supalla (1982). For more recent work, see Emmorey (2003) and the references therein.

24 See Kaplan (1977) for the interpretation of the operator d-that in the translation of the verb.

\section{Works Cited}

Anand, P., and A. Nevins. 2004. Shifty operators in changing contexts. Proceedings of SALT 14, ed. by Watanabe Kazuha and Robert B. Young, 20-37. Ithaca, NY: CLC Publications.

Benjamin, B. 1996. Non-manual realization of agreement in American Sign Language PhD thesis, Boston University.

Benedicto, E., and D. Brentari. 2004. Where did all the arguments go? Argument changing properties of classifiers in American Sign Language. Natural Language and Linguistic Theory 22(4). 783-810.

Cecchetto, C., C. Geraci, and S. Zucchi. 2006. Strategies of relativization in Italian Sign Language. Natural Language and Linguistic Theory 24(4). 945-75.

—, and A. Zucchi. 2006. Event descriptions and classifier predicates in sign languages. Talk presented at the workshop on Lexicon, syntax, and events in honor of Anita Mittwoch. Jerusalem: Hebrew University of Jerusalem. 
Chierchia, G. 1995. Dynamics of meaning: Anaphora, Presupposition, and the theory of grammar. Chicago: The University of Chicago Press.

Cogill-Koez, D. 2000. Signed language classifier predicates: linguistic structures or shematic visual representation? Sign Language and Linguistics 3(2). 153-207.

Cooper, R. 1979. The interpretation of pronouns. Syntax and semantics 10. ed. by F. Heny and H. Schnelle, 61-92, New York: Academic Press.

Cruz Aldrete, M. 2008. Gramática de la Lengua de Señas Mexicana. PhD thesis, Colegio de México.

Emmorey, K. (ed.) 2003. Perspectives on classifier constructions in sign languages. Mahwah, New Jersey: Lawrence Erlbaum Associates.

- and M. Herzig. 2003. Categorical versus gradient properties of classifier constructions in ASL. Perspectives on classifier constructions in sign languages, ed. by K. Emmorey, 221-46. Mahwah, NJ: Lawrence Erlbaum Associates.

—

Evans, G. 1977. Pronouns, quantifiers and relative clauses (1). The Canadian Journal of Philosophy 7. 467-536. Reprinted in: Evans, G., 1985, Collected papers, Dordrecht: Foris, pp. 76-152.

- 1980. Pronouns. Linguistic Inquiry 11(2). 337-62.

Friedman, L. A. 1975. Space, time, and person reference in American Sign Language. Language 51(4). 940-61.

Geach, P. T. 1962. Reference and generality. Ithaca, New York: Cornell University Press.

Giacomello, S. 2007. I classificatori nella lingua italiana dei segni. Master's thesis, Università degli Studi di MilanoBicocca.

Groenendijk, J., and M. Stokhof. 1990. Dynamic montague grammar. Papers from the second symposium on logic and language, ed. by L.Kálmán and L. Pólos, 3-48. Budapest: Akadémiai Kiadó.

— , and - 1991. Dynamic predicate logic. Linguistics and Philosophy 14(1). 39-100.

Heim, I. 1982. The semantics of definite and indefinite Noun Phrases, PhD thesis, Amherst, Mass: University of Massachusetts, Published in 1989 by Garland, New York.

1990. E-type pronouns and donkey anaphora. Linguistics and Philosophy 13(2). 137-78.

1997. Tense in compositional semantics: introduction. Handout for the MIT seminar on Tense, Aspect and Events, Spring 1997.

Hyman, L. (ed.) 1979. Aghem Grammatical Structure, Vol. 7 of Southern California Occasional Papers in Linguistics. Los Angeles: University of Southern California.

Kamp, H. 1981. A theory of truth and semantic representation. Formal methods in the study of language, ed. by J.Groenendijk, T. Janssen and M. Stokhof, 277-322. Amsterdam: Mathematical Centre. Reprinted in J. Groenendijk, T. Janssen, and M. Stokhof (eds.), Truth, Interpretation and Information. Foris, Dordrecht, 1984.

—

Kaplan, D. 1977. Demonstratives. Manuscript, University of California at Los Angeles. Published in J. Almog, J. Perry, and H. K. Wettstein (eds.), Themes from Kaplan. 1989, pp. 481-563. New York: Oxford University Press.

Lee, R. G., C. Neidle, D. MacLaughlin, B. Bahan, and J. Kegl. 1997. Role shift in ASL: a syntactic look at direct speech. Syntactic structure and discourse function: an examination of two constructions in American Sign Language, ed. by C. Neidle, D.MacLaughlin and R. G. Lee, 24-45. Boston, MA: Boston University, American Sign Language Linguistic Research Project Report No. 4.

Lewis, D. K. 1980. Index, context, and content. Philosophy and grammar, ed. by S. Kanger and S. Öhman, 79-100. Dordrecht: Reidel.

Liddell, S. K. and R. E. Johnson. 1987. An analysis of spatial-locative predicates in American Sign Language. Paper presented at the Fourth International Symposium on Sign Language Research.

Lillo-Martin, D. 2002. Where are all the modality effects? Modality and structure in signed and spoken languages ed. by R. P.Meier, K. Cormier and D. Quinto-Pozos, 241-62. Cambridge: Cambridge University Press.

- 1995. The point of view predicate in American Sign Language. Language, gesture, and space, ed. by K. Emmorey and J. Reilly, 155-70. Hillsdale, NJ: Lawrence Erlbaum Associates.

— language research, ed. by S. D. Fischer and P. Siple, 191-210. Vol. 1 Linguistics, Chicago: University of Chicago Press.

Macken, E., J. Perry, and C. Haas. 1993. Richly grounding symbols in ASL. Sign Language Studies (81). 375-94.

Meier, R. P. 1990. Person deixis in American Sign Language. Theoretical issues in Sign Language research, ed. by S. D. Fischer and P. Siple, Vol. 1 Linguistics, 175-90. Chicago: University of Chicago Press.

Meir, I. 1999. A perfect marker in Israeli Sign Language. Sign Language and Linguistics 2(1). 43-62.

Neidle, C., J. Kegl, D. MacLaughlin, B. Bahan, and R. G. Lee. 2000. The syntax of American sign language: functional categories and hierarchical structure. Cambridge, Mass: MIT Press.

Padden, C. 1988. Interaction of morphology and syntax in American Sign Language. Outstanding dissertations in linguistics, New York: Garland Press. 
Parsons, T. 1978. Pronouns as paraphrases. Manuscript, Amherst: University of Massachusetts.

Petronio, K. 1995. Bare noun phrases, verbs, and quantification in ASL. Quantification in natural languages, Vol. 2, ed. by E. Bach, E. Jelinek, A. Kratzer and B. H. Partee, 603-17. Dordrecht: Kluwer.

Pizzuto, E., E. Cameracanna, S. Corazza, and V. Volterra. 1995. Terms for spatio-temporal relations in Italian Sign Language. Iconicity in language, ed. by R. Simone, 237-56. Amsterdam: John Benjamins.

Quer, J. 2005. Context shift and indexical variables in sign languages. Proceedings from semantics and linguistic theory 15, ed. by E. Georgala and J. Howell, 152-68. Ithaca, NY: CLC Publications.

Rathmann, C. G. 2005. Event structure in American Sign Language, PhD thesis, University of Texas at Austin.

Schalber, K. 2006. Event visibility in Austrian Sign Language (ÖGS). Sign Language \& Linguistics 9(1/2). $207-31$.

Schlenker, P. 1999. Propositional attitudes and indexicality (A cross-categorial approach) PhD thesis, M.I.T.

- 2003. A plea for monsters. Linguistics and Philosophy 26. 29-120.

2009. Donkey anaphora in French sign language (LSF). Forthcoming in Proceedings of NELS 40.

. 2010a. Donkey anaphora in sign language I: E-type vs. dynamic accounts. Logic, language and meaning:

17th Amsterdam colloquium, Vol. 6042 of lecture notes in computer science, ed, by M. Aloni, H. Bastiaanse,

T. deJager and K. Schulz, 405-15. Berlin: Springer.

- 2010b. Donkey anaphora: the view from sign language (ASL and LSF). Paris: Institut Jean Nicod, CNRS; New York University.

Smith, C. S. 2003. Modes of discourse: the local structure of texts, Cambridge: Cambridge University Press.

- 2004. The domain of tense. The syntax of time, ed. by J. Guéron and J. Lecarme, 597-619. Cambridge, MA: MIT Press.

Speas, M. 2000. Person and point of view in Navajo direct discourse complements. Papers in honor of Ken Hale, Vol. 1 of MIT working papers on endangered and less familiar languages, ed. by E. Jelinek, A. Carnie and M. A. Willie, Cambridge, MA: MIT.

Supalla, T. 1982. Structure and acquisition of verbs of motion and location in American Sign Language, PhD thesis, University of California at San Diego.

- 1990. Serial verbs of motion in ASL. Theoretical issues in sign language research, Vol. I: linguistics, ed. by S. D. Fischer and P. Siple, 127-52. Chicago: The University of Chicago Press.

Valli, C., and C. Lucas. 2000. Linguistics of American Sign Language: an introduction 3rd edn, Washington, DC: Gallaudet University Press.

Wilbur, R. B. 2003. Representations of telicity in ASL. Papers from the 39th Regional Meeting of the Chicago Linguistic Society, Chicago. 354-68.

Zucchi, S. 2004. Monsters in the visual mode? Talk presented at Sinn und Bedeutung 10, Humboldt University, Berlin, October 13 - 15, 2005.

- 2009. Along the time line: tense and time adverbs in Italian Sign Language, Natural Language Semantics 17. 99-139. 